\title{
Tacit Knowledge Sharing Modes of University Teachers from the Perspectives of Psychological Risk and Value
}

\author{
Dengke $\mathrm{Yu}^{1} \&$ Rong $\mathrm{Zhou}^{2}$ \\ ${ }^{1}$ School of Management, Nanchang University, Nanchang, China \\ ${ }^{2}$ School of Economics and Management, Jiangxi Science \& Technology Normal University, Nanchang, China \\ Correspondence: Dengke Yu, Dep. of Management Science and Engineering, School of Management, Nanchang \\ University, Nanchang 330031, China. Tel: 86-151-8016-7663. E-mail: yudengke@ncu.edu.cn
}

Received: April 14, 2015

Accepted: April 27, $2015 \quad$ Online Published: April 28, 2015

doi:10.5430/ijhe.v4n2p214

URL: http://dx.doi.org/10.5430/ijhe.v4n2p214

\begin{abstract}
Tacit knowledge sharing (TKS) is important to improve the teaching skill and researching knowledge of university teachers. In this paper, the tacit knowledge sharing of university teachers is catalogued as four modes from perspectives of the psychological risk and psychological value which are measured by two grades - high and low. The four modes are named "Peer-review", "Learning Community", "Thumb-a-lift" and "Academic Conference", which are characterized by different values and risks. Some suggestions are proposed to promote the tacit knowledge sharing of university teachers.
\end{abstract}

Keywords: Knowledge management, Tacit knowledge sharing, Mode, University teacher, Psychological risk, Psychological value

\section{Introduction}

Knowledge sharing (KS) is important to promote the professional skill and competence of university teachers (Huo, 2013; Semradova and Hubackova, 2014) in knowledge age. The reasonability of a university teacher reflects not only the specialization and research but also the teaching and cultivating talents (Semradova and Hubackova, 2014). University teachers are normally characterized with knowledge, innovation and high-quality. In fact, the scale of university teacher is large, and the qualities of university teachers are irregular (Huo, 2013). Along with the refining of major, knowledge and field, the comprehensive knowledge and skill of university teachers are required update constantly. It's essential to extending and expanding their knowledge systems, in order to break through the bottleneck of the development of professional quality. The theoretical knowledge and working knowledge are created and renewed with a much higher rapid in the era of knowledge economy. It's necessary to investing in software and hardware as well as constructing organizational culture and promoting KS to build a sustainably developed high-level team of university teacher (Costa and Monteiro, 2012).

How to promote TKS among university teachers? Research of the mode and mechanism of TKS among university teachers is meaningful for providing some suggestions. In the knowledge system of university teacher, the knowledge can be classified as tacit knowledge and explicit knowledge (Gao, 2013). The tacit knowledge, which is naturally reflected in the process of teaching and researching, is valuable as well as competitive for the university teachers (Venkitachalam and Busch, 2012). The tacit knowledge has characters such as being beyond expression, difficult to normalize, and individual as well as independent. However, it would deeply influence the value, thought, and emotion of the university teachers as well as their organizational abilities, teaching methods, skills, experience and researching capabilities. In the process of teaching and researching, the tacit knowledge may be created at all times. This knowledge would create value for others. However, a university teacher is required to learn from others at the same time of knowledge output. Hence, to build a bidirectional and equal knowledge transfer channel is essential to the TKS. Balancing the output and input of knowledge is necessary to the continuing KS. Currently, the problems about TKS in university teacher team constitute the main factors which influence the professional development of university teachers (Huo, 2013).

However, there are many barriers to the TKS among university teachers. A question we have to answer is that what influential factors are the key of TKS. Are the psychological factors such as reputation, trust or psychological distance mentioned by some researchers? From the psychology perspective, the TKS activities follow a kind of 
rational principles (Xiaojun et al., 2011). In the decision-making process of TKS, university teachers would weigh the potential risks and values when they share their own knowledge with others (Ranasinghe and Dharmadasa, 2013). Only when they recognize that the values are higher than the risks, the evaluation results would be active and then the TKS would become a priority. This evaluation is made on the basis of psychological preference, and so it may be influenced by the some factors such as experience, knowledge and environment. Even on the same condition, different teachers may gain the totally different evaluation results and then reflect discrepant behaviors. Consequently, the psychological value and risk of TKS would be discussed in this paper and are set as two dimensions for cataloguing the TKS modes.

Hence, the main aims of this research are twofold: first, to analyze and catalogue the TKS modes of university teachers from a new perspective; second, to propose some suggestions to promote the TKS of university teachers. The first aim is full of theoretical values and the second aim is meaningful to guide the practical activities.

Correspondingly, the remainder of this paper is structured as follows. Some literatures concerned the TKS mode are reviewed in Section 2. The basic conceptions would be introduced and analyzed in the Section 3. In Section 4 the TKS modes would be catalogued from the two dimensions. The corresponding suggestions would be proposed in Section5. The findings and conclusions would be summarized in Section 6.

\section{Literature review}

Knowledge sharing (KS), as a vital component of knowledge management process (Cabrera and Cabrera, 2002), is an increasingly important topic in today's connected world (Stewart, 2012). Many researchers have discussed the relevant topics of KS including KS strategy (Bektas, 2013; Puccinelli, 1998; Sita Nirmala Kumaraswamy and Chitale, 2012), KS process (El Harbi et al., 2011; Sivak and Koch, 2012; Tsai, 2014), KS system (R and Prakasam, 2013; Song, 2002; Yoo and No, 2014), KS barrier (Kaps, 2011; Sharma, 2015; Wendling et al., 2013) and KS mechanism (Bij et al., 2006; Chai et al., 2003; Kohansal et al., 2013) and so on. The knowledge sharing research has been involved in a broad range from team(Hu et al., 2009; Zhang and Fai Ng, 2012) and organization (Lauring and Selmer, 2012; Yang and $\mathrm{Wu}, 2008$ ) to industry (Ahmadi et al., 2012; Connell et al., 2014). Tacit knowledge is a significant and most valuable element of knowledge (Chase, 2007). Hence, many researchers studied the topic about tacit knowledge and published many important achievements (Jabar et al., 2010; Matoskova et al., 2013; Tschetter and Tschetter, 2012). Thereinto, sharing tacit knowledge was one of the most popular topics (Borges, 2013; Suppiah and Sandhu, 2011).

However, only a few literatures discussed the mode of KS, and the literatures concerned the mode of TKS are even rare. Yoon et al. (2011) classified three collaboration modes of KS. Those were No Corroboration, Information Sharing and Information Sharing with Best Practice Knowledge-base. Based on the Delphic method, Oliver (2014) identified five distinctive modes of KS summarized them as two types: fast KS and slow KS. Nicholls and Cargill (2010) studied the best practice manufacturing on basis of TKS through the mixed mode of "soft" and "hard" models. The TKS behavior of university teacher, who is an important kind of knowledge talents, attracted many interests of researchers. Li et al. (2011) analyzed major factors for KS among faculty members and proposed that the achievement of individual motivations was the most influential factor for faculty KS. Chen (2011) explored some knowledge-sharing behaviors of high-school teachers and several exogenous variables were identified as the influential factors. Xiaojun et al. (2011) found that the different dimensions of psychological contracts played different roles on university teachers' KS. Xiaohui (2012) found that the obstacles of university teachers' KS mainly lied in the cultural, institutional and technical aspects. Zhong and Qu (2012) constructed a model of teachers' tacit knowledge based on social software, in order to bring about a new viewpoint as well as a new thought pattern for the current sharing of teachers' tacit knowledge. Costa and Monteiro (2012) based on a survey of 162 university teachers examined the relationship between organizational commitment and KS. Huo (2013) analyzed the KS process model of university teacher team, and studied the influencing mechanism for promotion of TKS.

At the most of time, university teacher plays the role of researcher or scientist. Consequently, the research achievements of TKS among researchers or scientists also have reference significance for the authors. For example, Cornelissen et al. (2011) proposed a kind of school-university research network for closer integration of research and practice by means of teacher research, and then abstracted fifteen network aspects for promotion of KS processes. Ismail (2012) ascertained the nature and the process of sharing research-knowledge in higher education institutions in general, and examined the influence of the desired key determinants on research-KS in particular. As Buntrock (2009) mentioned, psychological factors such as reputation would influence the KS among scientists and then impact on the R\&D performance of multinational firms. Other researchers presented the similar views on KS among scientists (Ensign, 2002; Kekäle, 2011). 
To sum up, it can be found that (1) KS and TKS were all popular topics of knowledge management, and many researchers paid attention to those topics concerned KS and TKS; however, (2) there were just a few publications concerned the mode of KS or TKS; fortunately, (3) the fruitful achievements about KS among university teachers, researchers or scientists can provide sufficient reference for the authors. This study would contribute a lot to theoretical development of TKS among university teachers and mode of TKS. The special researcher view - from psychology perspective - would increase the theoretical innovation value of this study.

\section{Basic conceptions}

\subsection{Tacit knowledge sharing}

The term "tacit knowledge" was first introduced by Polanyi (1966). It was stated as the kind of knowledge (e.g. abilities, developed skills and experience, etc.) that is highly personal and difficult to reduce to writing (Holste and Fields, 2010). Because the tacit knowledge is always stored in peoples' brains, capturing, codifying, transferring and sharing tacit knowledge is one of the biggest challenges of knowledge management (Mládková, 2012). However, tacit knowledge is the main body of organizational knowledge with a priority and is the key to form the individual and organizational innovation capability (Liu and Cui, 2012). Consequently, processing, sharing and using tacit knowledge is an essential and unavoidable issue of every organization. Research of the TKS mechanism has received significant attention. Many researchers studied the relevant issues such as initiative (Gubbins et al., 2012), barrier (Okoroafor, 2014), context (Shariq, 2010), approach (Ting et al., 2011) and tool (Panahi et al., 2013) for TKS.

Some literatures became to focus on the research of TKS among teachers, academics or researchers in universities (Scharf, 2008; Shim and Roth, 2007; Zhong and Qu, 2012). Even a few of them involved in the perspective of psychology (Xiaojun et al., 2011), since the behavior of TKS often depends on social psychology rather than knowledge technology. The intension of KS is to backward improve the utility of knowledge. The nature of KS relationship is psychological contract among different university teachers, which are nodes in the informal knowledge networks. The frequent cooperation is common to university teachers, as they always do team work for researching and teaching. Consequently, it can be found that the TKS activities, accompanying with the activities such as cooperative knowledge creation and knowledge utilization, always occurred in university teacher teams.

\subsection{Psychological risk}

Much research shows that the psychological risk or psychological safety is an important influential factor of TKS, and its level is directly depended on the degree of the psychological risk (Humphery-Jenner, 2013; Kessel et al., 2012; Nugroho, 2012; Siemsen et al., 2009; Zhang et al., 2010). In the process of teaching, the university teachers would not face risks of potential loss because of the worry about sharing knowledge and losing competence. The knowledge transferred from teachers to students is low-innovativeness and low-value. The different roles of the students and the teachers also reduce the risks of KS which are brought by losing competence after sharing knowledge.

However, when the university teachers communicate together in process of teaching discussion or academic cooperation, they would always face some psychological risks as follows. On the one hand, the teachers who are lack of self-confidence and creative knowledge would worry about being laughed, underestimated or marginalized. On the other hand, the teachers who are knowledgeable and creative would face the risks of losing peculiarity and competence if their ideas are plagiarized, copied and transferred. Hence, the ad joint variances of the psychological risk are psychological safety and trust. The key to reduce the psychological risk and in turn promote the TKS is to build psychological contract among university teachers and enhance the level of psychological safety or trust (Whalan, 2012; Xiaojun et al., 2011).

\subsection{Psychological value}

Much literatures have discussed that the intention of KS is mainly sourced from psychological values such as reputation, respect and self-worth (Emelo, 2012; Ensign and Hebert, 2010; Ensign, 2009; Jolaee et al., 2014; Xue et al., 2012). The intention of KS behavior of university teachers is the positive effect, namely psychological value. The psychological values can be catalogued as two varieties. The first one is the value of new knowledge (e.g. skill, method, idea and secret of success) gained in the KS process from the knowledge resource exchange perspective. The second one is the self-worth which means the enhancement of competency and self-efficacy from the happiness and satisfaction of KS, and the social value which includes peer respect, status, reputation and prestige won in the process of TKS (Galletta et al., 2003).

Aiming to gain more knowledge from the process of sharing, the short-sighted university teachers would like to share and exchange knowledge with others who are more knowledgeable than them. In fact, this kind of choice and preference limit the scale and scope of TKS. In contrast, aiming to win self-satisfaction and social value, the 
university teachers who have long-term version would not limit their KS reactors. Then, the scope, scale, quality and utility of TKS would be relatively more proper. Certainly, even the same university teacher would change the expected target when he faces different KS environments. The target is always exchanging and gaining new knowledge in the communication among university teachers at the similar level. The TKS activities among university teachers at the different levels may be usually inspirited by the social values.

\section{Modes of TKS}

From the above analysis, the psychological factors can be catalogued by two dimensions - risk and value. Every dimension can be measured by two grades - high and low. Then, the space of psychology can be divided into four quadrants: high-risk and high-value, low-risk but high-value, high-risk but low-value, and low-risk and low-value. Corresponding to the four quadrants, the TKS modes can also be catalogued as four types: "Peer-review", "Learning Community", "Thumb-a-lift" and "Academic Conference". The modes are named by their psychological characters. The psychological value and risk of four KS modes are shown in Figure 1.

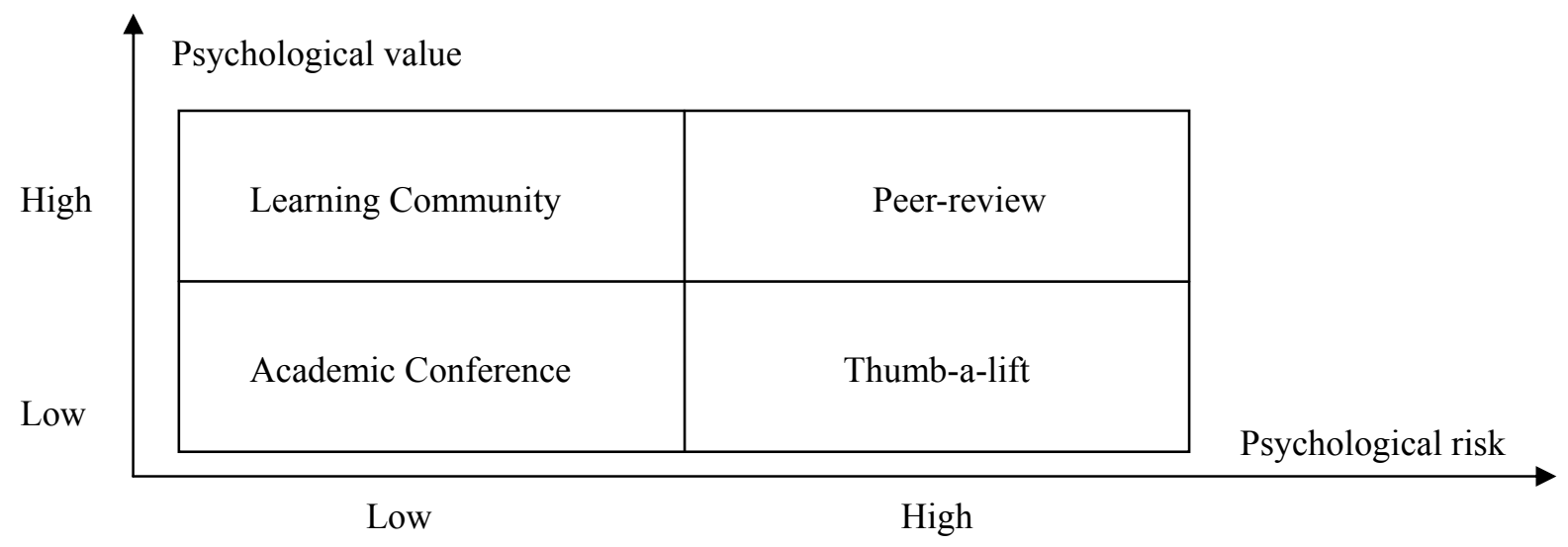

Figure 1. Four modes of TKS among university teachers

\subsection{TKS in the process of "peer-review"}

Peer review nowadays is standard practice that would encounter university teachers when they submit journal articles, apply for sponsorship of scientific foundation or evaluate the quality of teaching, etc. The mechanism of peer review is significant, not least safeguarding the quality or reputation of the journal. Most peer reviewers, who are usually knowledgeable, practiced and influential in the similar field, "take the job seriously, situating the submission within a wider field, ensuring the research is at the cutting edge, and offering constructive feedback, particularly important to new scholars" (Singleton, 2015). Furthermore, peer review is a necessary process for the continuing development of university teacher at all levels (Singleton, 2015), either working on research or teaching.

The peer reviewing is actually a valuable process of TKS. To the peer reviewers, they can read and share others' teaching skills or academic ideas, which may be significant to themselves improving skills and innovativeness. To the peer-reviewed teachers, they can gain feed-back suggestions and advices, and then improve their teaching and researching. TKS from peer review is a continuing process of experience accumulation for the future work.

However, the TKS in the process of peer review is highly risky. On the one hand, peer reviewers can easily gain valuable originalities from the reviewed submissions. Some academic dishonorable activities such as plagiarism, diffusion without authorization, and unreasonable criticism on purpose may happen when the peer reviewers are driven by interests (Shatz, 2004). Such activities bring losses of value as well as psychology to the peer-reviewed university teachers. On the other hand, the advices and suggestions from some impertinent peer reviewers are of no worth, but may mislead the research orientations of scholars. The unreasonable criticism may attack the confidence of the peer-reviewed teachers.

Hence, the selection of peer reviewers for the given submissions is significant. The evaluation indices should cover not only the correlation of major but also the level of honesty. In addition of high risk, the TKS in the process of peer review faces another shortcoming. The limited scale and scope of the TKS from peer review restrict the efficiency and value of this KS mode. 


\subsection{TKS in the "learning community"}

A learning community is a group of people, particularly university teachers here, who share academic ideas, skills, methods, experience and attitudes, or who meet semi-regularly to collaborate on teaching work (Richlin and Cox, 2004). The target of learning community is KS rather than knowledge learning as the name. In the learning community, the invisible connections are more important than the visible requirements to the cooperation among members. The structures of knowledge, experience and function etc. are usually different but fit each other for proper coordination of members. The cooperation among university teachers with different characters can better share and motivate creative ideas, and in turn solve the problems. The university teachers in the same learning community are cooperative rather than competitive, and so they can discuss and share views freely.

Compared with the lack of recognition and trust between the reviewer and the person who is peer reviewed in the process of peer review, the level of recognition and trust is much higher in the learning community. Through the frequent communications, the link among members adds emotional connections. Because of the high level of trust and strong emotional connection, the TKS in learning community is of low risk and high value inevitably.

The values for university teachers from learning community reflect on three aspects: first, sharing and accumulating concrete knowledge to solve specific problems of teaching or researching; second, constructing emotional connections with university teachers who own different knowledge, capability and skills to build normalized channels for high-level TKS; building academic reputation in the research field to fulfill self-worth and social value by contributing knowledge.

Certainly university teachers also may face risks, which depend on the quality of learning community in terms of culture, mechanism, platform, tool and organization. The high value and low risk of a learning community is decided by the strong cohesive force and proper knowledge attainment of members. The risk would increase when the learning community is only shaped but not connected.

In general, the university teachers in a given learning community would face with low risk, since they are restricted by explicit mechanism and latent connections. Compared with peer review, the number of members in learning community is not limited. The dynamic scale and scope of learning community guarantee the quality, efficiency, stability and continuity of TKS among university teachers in it.

\subsection{TKS by "thumb-a-lift"}

"Thumb-a-lift" is not a strictly mode of TKS. It is a generic term of TKS modes with the similar characters (Zeng, 2014). In these modes, for example, academic forum, teaching blogs and discussion space, such "thumb-a-lift" activities often happened. The "thumb-a-lift" behavior is motivated by human's selfish psychology. When "thumb-a-lift" may bring benefits and not be punished, such behavior always occurs.

"Thumb-a-lift" phenomenon exists in the TKS activities of university teachers. For example, many teachers log on some on-line learning and discussion webs to gain information and knowledge, but most of them do not contribute their own knowledge. Even some teachers would issue some information or knowledge on blogs or forums. The knowledge is often not as valuable as imagining.

The consequences of "thumb-a-lift" are two-fold. First, the distrust and reservation of university teachers make individual TKS difficult. Second, "lemon effect" would reflect in organizations. The members who have a lot of knowledge and strong willingness to share knowledge would exit the organization. And then the organization would be full of teachers who are at relatively lower level. Consequently, the "thumb-a-lift" would reduce the scale and quality of TKS.

In many modes of TKS, the risk and value of the same individuality are always concomitant. However, when the "thumb-a-lift" exists, the value and risk would be separated. The persons who thumb a lift gain value while persons who are thumbed face risks of psychological losses. Hence, this TKS mode is always not stable.

There are some preconditions in terms of organization, mechanism and quality for continuing development of such kind of KS modes with high risk and low value. First, the number of member should be big enough to guarantee the necessary amount of knowledge in the organization; second, the members are from different institutions and fields, so that the competition is not intense; third, some incentive mechanisms restrict the behaviors of members, and the members are required to contribute knowledge before gain it; finally, the knowledge which is shared is common and low-value, and so small risks would exist even when "thumb-a-lift" activities happen.

In this kind of organization, the number of member is large, and the contributors could not control the objects and orientation of TKS. The peculiarity and value of knowledge would be weakened rapidly if the valuable knowledge is 
shared without any control. That is to say, there are high risks in the mode of "thumb-a-lift".

\subsection{TKS in "academic conference"}

Academic conference is a popular mode of TKS for university teachers (Sumi and Mase, 2002). Many university teachers prefer to communication through international or national academic conferences to know others' new views and opinions.

Though academic conference is a proper mode for TKS, its value is limited. Several reasons cause that. First, the quality of the academic papers published in conferences is always not as good as the papers published in journals. Second, the topics discussed in a conference are generally extensive. University teachers who take part in the conferences always cannot find proper research achievements that match their interests. Most of achievements are not so valuable for reference. Third, many researchers would introduce their achievements, but they would not expect to gain many suggestions and advices. The TKS in academic conference is not deeper than the communication in the process of peer review. Finally, university teachers discuss the submissions in the conference. However, other topics may be lack of sharing and communication. Consequently, there are problems about quality, depth and scope of the TKS in academic conference. University teachers can increase the frequency of academic conferences to gain and accumulate more knowledge. Then, the value of TKS through academic conference may reflect.

The risk with TKS through academic conference is small. First, the academic submissions are always published publicly, and so the worry about plagiarism is not needed. Second, the communication in the conference is often limited in the published paper. The scope and depth of KS are restricted, and the risk is limited correspondingly. Third, the KS process in conference is face-to-face, and the whole sharing process is controllable. The behavior of "thumb-a-lift" can be avoided. Certainly, there may be some psychological risks of TKS in academic conferences. The expected value does not match the real value. Suck kind of psychological risk is really small and can be adjusted through relaxing oneself.

\section{Suggestions}

Corresponding to the four modes of TKS and their characters with psychology value and risk, some suggestions are proposed to promote the TKS among university teachers from the perspectives of increasing value and controlling risks.

\subsection{Normalizing the appraisal mechanism of peer's capability and morality}

In the mode of "peer-review", the value of TKS depends on the knowledge and capability of peers, whilst the risk depends on the morality and quality. The appraisal of peer's capability and morality guarantees the quality, justice and fairness; so, the construction of appraisal mechanism should be the core contents of peer-review system. The capability appraisal needs to consider the factors such as knowledge and experience in terms of authority, frontier and correlation. The morality appraisal should cover the evaluation of peer's integrity and responsibility. The reviewers should share knowledge and contribute advices fairly, and faithfully criticize and deal with others' creative achievements.

The requirements for normalizing the appraisal mechanism of peer's capability and morality are twofold. On the one hand, the capability and morality should be introduced as key indices in system of peer selection. Only the specialists who match the requirements of capability, morality and knowledge structure can be selected as peer reviewer. On the other hand, the capability and morality should be introduced in post-assessment system. Only the reviewers who contribute suggestions and share knowledge, with integrity and responsibility, can reserve the qualification of peer reviewer; else they would be punished psychologically with bad integrity records.

On the basis of effective design of appraisal mechanism, the operability and power of execution should be enhanced, to guarantee the quality and safety of TKS in the process of peer-review.

\subsection{Building mechanism of incentive equilibrium}

The aim realization of learning community requires the cooperation of lots of members with the same target but different knowledge structure. Then, a real and concrete problem would emerge. That is, how to distribute the benefit when the aim does realize? In other words, how to balance the motivation to promote the KS and collaboration? Consequently, building mechanism of incentive equilibrium in learning community is essential.

The key factors of incentive equilibrium are as follows: first, to effectively motivate university teachers to forwardly share their tacit knowledge with high quality and high efficiency; second, to balance the benefit distribution among teacher members to guarantee their psychological equilibrium, and in turn enhance the willingness of knowledge 
sharing. Since the aim of most of teacher members is to acquire knowledge in learning community, the best motivator is to increase the level and value of KS. In addition, the proper material motivation and spiritual motivation are also useful for improvement of TKS.

The incentive equilibrium needs the construction of assessment system of different teachers' contributions on organizational target realization. Only when the incentive measures match the contribution value, the fair motivation is effective to TKS of university teachers with optimistic and peaceful psychology. Hence, it is important to build mechanism of incentive equilibrium by balancing the contribution and benefit, and the value and risk, on the basis of assessment of knowledge contribution, for improvement of long-term continuing TKS in learning community.

\subsection{Avoiding the "thumb-a-lift" behavior in process of KS}

Sometimes it is difficult to avoid the thumb-a-lift problem in a loose KS organization with little restriction. Just because of this, to avoid the thumb-a-lift problem and reduce the risk is an effective measure for improvement of the level and quality of TKS among university teachers.

The measures of avoiding the "thumb-a-lift" behavior in process of TKS among university teachers include two aspects. First, it is needed to promote the willingness, consciousness and capability of TKS by controlling the qualification of admittance and withdrawal of teacher members. Only the university teachers with high willingness and level of TKS can be introduced in knowledge organizations. Second, to guide and restrict the KS behavior by mechanism and standards is required. For example, to provide compensation for teachers who contribute knowledge, and to restrict the authority, qualification and frequency of knowledge acquirement of the members who contribute little knowledge. Another measure for reducing the influence from thumb-a-lift to KS willingness is to eliminate the negative effects of thumb-a-lift. Even the thumb-a-lift behavior is encouraged to increase the number of sharers, and in turn improve the possibility of sharing valuable knowledge.

It is hard to define and distinguish the thumb-a-lift behavior, and even harder to punish and avoid this problem. The effective measures for solving this kind of problem are avoiding thumb-a-lift behavior and reducing risk by introduction of scientific mechanism, and reducing the negative effects by effective methods.

\subsection{Improving the scale, frequency and quality of academic conference}

Because the TKS mode of academic conference is characterized by low value as well as low risk, the measures for improvement of TKS level in academic conference are twofold: first, to improve the KS value from each academic conference; second, to increase the frequency of taking part in academic conference.

There are two methods to improve KS value from each academic conference. First, try best to select the large-scale academic conferences to enhance the possibility of matching the knowledge supply and demand. Second, try best to select the strongly correlative and high-quality academic conference to increase the value of knowledge.

Because the risk of KS in academic conference is low, the requirements for controlling risk are low. When the number of academic conference increases, the risk would be further spread. Hence, the best choice for university teachers is to take part in lots of academic conferences with large scale and high quality. From the view of sponsor of academic conference, the requirements include enhancing the quality and popularity of academic conference and increasing the scale and scope of participants, and in turn improving the total added value for participants involving themselves in this kind of mode of TKS.

\section{Conclusion remarks}

KS is one of core contents of individual knowledge management of university teachers. TKS is the most valuable among kinds of KS. As an important kind of knowledge talents, university teacher is performer of knowledge storing, transferring, diffusing, creating and using. The knowledge sharing would improve the knowledge quality and teaching skill of university teachers, and make them provide better services for education, research and social development. However, to promote TKS of university teachers is also a problem needed to be resolved currently. The factors, motivators, targets, mechanisms, principles and modes of TKS among university teachers are required to be studied.

From the perspectives of psychological value and risk, this paper summarizes and analyzes four modes of TKS among university teachers. The main findings of this study can be summarized as follows. First, the TKS is a kind of rational behavior of university teachers who make the decision on the comparative consideration of psychological value and psychological risk. Second, the psychological value and risk are both weighted by grades "high" and "low" and the university teachers would face different levels of psychological value and risk when they share tacit knowledge with different modes. Third, corresponding to the four quadrants which are divided by psychological 
value and risk, the TKS modes of university teachers can be catalogued as four modes, namely, "Peer-review", "Learning Community", "Thumb-a-lift" and "Academic Conference". Fourth, different factors cause the different characters on psychological value and risk of the four modes. Finally, corresponding to the different psychological characters and the caused factors, different suggestions are provided to promote the TKS among university teachers.

The main implications of this study are for professionals concerning theoretical innovation about TKS and practical application of knowledge management for teacher teams. This theory provides a new view and thought for studying the internal mechanism and external expression of TKS, and in turn offers a new orientation for solving the problem of promoting TKS among university teachers. Some practitioners may begin to rethink the strategy, mechanism or communication system of TKS in the past.

Indeed there are some limitations of this study. For instance, the rationality and systematization of the four TKS modes are required to be researched deeply; case study or empirical analysis are required for measurement of psychological value and risk in process of TKS on condition of the four modes; the effects of the four kinds of suggestions need to be verified.

More in-depth research is needed to enrich the theory proposed in this paper. Some methods, tools and systems are required to be developed and updated for promote the TKS among university teachers, from the perspectives of psychological value and risk. Themes such as how to embed psychological theories in TKS practices and how to measure and balance the psychological value and risk of TKS, would arouse interesting of many researchers.

\section{Acknowledgement}

This work was supported by the National Natural Science Foundation of China (Grants No. 71201072) and Postgraduate Education Reform Foundation of Jiangxi Province in China (Grants No. JXYJG-2014-015). The authors wish to acknowledge the China Scholarship Council for its funding support and the Queensland University of Technology, Australia for providing necessary research facilities and supervision.

The authors declare that there is no conflict of interests regarding the publication of this article.

\section{References}

Ahmadi, S.A.A., Daraei, M.R., Kalam, R.F. (2012). "Analysis of knowledge sharing in banking industry", Interdisciplinary Journal of Contemporary Research In Business, Vol. 4 No. 7, PP. 815-827.

Bektas, E. (2013). "Knowledge sharing strategies for large complex building projects", Architecture and the Built Environment, Vol. 3 No. 4, PP. 1-332. http://dx.doi.org/10.7480/abe.2013.4

Bij, v.d., JD, Berends, J., Debackere, K., Weggeman, M. (2006). "Knowledge sharing mechanisms in industrial research", R\&D Management, Vol. 36 No. 1, PP. 455-482. http://dx.doi.org/10.1111/j.1467-6486.2009.00870.x

Borges, R. (2013), "Tacit knowledge sharing between IT workers", Management Research Review, Vol. 36 No. 1, PP. 89-108. http://dx.doi.org/10.1108/01409171311284602

Buntrock, R.E. (2009). "Knowledge sharing among scientists: why reputation matters for R \& D in multinational firms", Critical Perspectives on International Business, Vol. 5 No. 4, PP. 319-321. http://dx.doi.org/10.1108/17422040911003060

Cabrera, Á., Cabrera, E.F. (2002). "Knowledge-sharing dilemmas", Organization Studies, Vol. 23 No. 5, PP. 687-710. http://dx.doi.org/10.1177/0170840602235001

Chai, K.-H., Gregory, M., Shi, Y. (2003). "Bridging islands of knowledge: a framework of knowledge sharing mechanisms", International Journal of Technology Management, Vol. 25 No. 8, PP. 703-727. http://dx.doi.org/10.1504/IJTM.2003.003133

Chase, R.L. (2007). "Tacit knowledge", Journal of Knowledge Management, Vol. 11 No. 1, PP. 337-366. http://dx.doi.org/10.1007/s11097-011-9251-x

Chen, C.-C. (2011), "Factors affecting high school teachers' knowledge-sharing behaviors", Social Behavior and Personality, Vol. 39 No. 7, PP. 993-1008. http://dx.doi.org/10.2224/sbp.2011.39.7.993

Connell, J., Kriz, A., Thorpe, M. (2014). "Industry clusters: an antidote for knowledge sharing and collaborative innovation?", Journal of Knowledge Management, Vol. 18 No. 1, PP. 137-151. http://dx.doi.org/10.1108/JKM-08-2013-0312

Cornelissen, F., van Swet, J., Beijaard, D., Bergen, T. (2011). "Aspects of school-university research networks that play a role in developing, sharing and using knowledge based on teacher research", Teaching and Teacher Education, Vol. 27 No. 1, PP. 147-156. http://dx.doi.org/10.1016/j.tate.2010.07.011 
Costa, V., Monteiro, S. (2012). Knowledge sharing among university teachers: the role of organizational commitment, European Conference on Knowledge Management. Academic Conferences International Limited, Portugal, pp. 226-233.

El Harbi, S., Anderson, A.R., Amamou, M. (2011). "Knowledge sharing processes in Tunisian small ICT firms", Library Review, Vol. 60 No. 1, PP. 24-36. http://dx.doi.org/10.1108/00242531111100559

Emelo, R. (2012). "Why personal reputation matters in virtual knowledge sharing", Industrial and Commercial Training, Vol. 44 No. 1, PP. 35-40. http://dx.doi.org/10.1108/00197851211193408

Ensign, P., Hebert, L. (2010). "How reputation affects knowledge sharing among colleagues", MIT Sloan Management Review, Vol. 51 No. 2, PP. 79-81.

Ensign, P.C. (2002). Reputation and technological knowledge sharing among R\&D scientists in the multidivisional, multinational firm. HEC Montreal (Canada), ProQuest, UMI Dissertations Publishing.

Ensign, P.C. (2009), Knowledge sharing among scientists : why reputation matters for R\&D in multinational firms. Palgrave Macmillan, New York, United States.

Galletta, D.F., Marks, P.V., Polak, P., McCoy, S. (2003). "What leads us to share valuable knowledge? An experimental study of the effects of managerial control, group identification, and social value orientation on knowledge-sharing behavior", 36th Annual Hawaii International Conference on System Sciences, Hawaii, IEEE Computer Society, PP. 1-10. http://dx.doi.org/10.1109/HICSS.2003.1174271

Gao, Y. (2013). "The knowledge management of university teachers based on information technology", Advanced $\begin{array}{llllll}\text { Matericals Research, } & \text { Vol. } & 765-767 & \text { No., } & \text { PP. } & \text { 3282-3284. }\end{array}$ http://dx.doi.org/10.4028/www.scientific.net/AMR.765-767.3282

Gubbins, C., Corrigan, S., Garavan, T.N., O' Connor, C., Leahy, D., al, e. (2012). "Evaluating a tacit knowledge sharing initiative: a case study", European Journal of Training and Development, Vol. 36 No. 8, PP. 827-847. http://dx.doi.org/10.1108/03090591211263558

Holste, J.S., Fields, D. (2010). "Trust and tacit knowledge sharing and use", Journal of Knowledge Management, Vol. 14 No. 1, PP. 128-140. http://dx.doi.org/10.1108/13673271011015615

Hu, M.-L.M., Horng, J.-s., Sun, Y.-H.C. (2009). "Hospitality teams: knowledge sharing and service innovation performance", Tourism Management, Vol. 30 No. 1, PP. 41-50. http://dx.doi.org/10.1016/j.tourman.2008.04.009

Humphery-Jenner, M. (2013). "Diversification in private equity funds: On knowledge sharing, risk aversion, and limited attention", Journal of Financial and Quantitative Analysis, Vol. 48 No. 5, PP. 1545-1572. http://dx.doi.org/10.1017/S0022109013000501

Huo, M. (2013). "Analysis of knowledge-sharing evolutionary game in university teacher team", International Journal of Higher Education, Vol. 2 No. 1, PP. 60-66. http://dx.doi.org/10.1007/978-3-8349-6217-1

Ismail, N.A.M. (2012). Key determinants of researcher-knowledge sharing in UK higher education institutions. University of Portsmouth, UMI Dissertations Publishing, United States.

Jabar, M.A., Sidi, F., Selamat, M.H. (2010). "Tacit knowledge codification", Journal of Computer Science, Vol. 6 No. 10, PP. 1170-1176. http://dx.doi.org/10.3844/jcssp.2010.1170.1176

Jolaee, A., Nor, K.M., Khani, N., Yusoff, R.M. (2014). "Factors affecting knowledge sharing intention among academic staff", The International Journal of Educational Management, Vol. 28 No. 4, PP. 413-431. http://dx.doi.org/10.1108/IJEM-03-2013-0041

Kaps, I. (2011). "Barriers in intercultural knowledge sharing", Open Journal of Knowledge Management, Vol., No. 3, PP. 6-12.

Kekäle, T. (2011). "Knowledge sharing among scientists", Journal of Workplace Learning, Vol. 23 No. 7, PP. 483-484. http://dx.doi.org/10.1108/jwl.2011.23.7.483.1

Kessel, M., Kratzer, J., Schultz, C. (2012). "Psychological safety, knowledge sharing, and creative performance in healthcare teams", Creativity and innovation management, Vol. 21 No. 2, PP. $147-157$. http://dx.doi.org/10.1111/j.1467-8691.2012.00635.x

Kohansal, M.A., Alimoradi, Z., Bohloul, S.M. (2013). "The impact of knowledge-sharing mechanisms on employee performance", International Journal of Business Performance Management, Vol. 14 No. 3, PP. 293-306. http://dx.doi.org/10.1504/IJBPM.2013.054954

Lauring, J., Selmer, J. (2012). "Knowledge sharing in diverse organisations", Human Resource Management Journal, Vol. 22 No. 1, PP. 89-105. http://dx.doi.org/10.1111/j.1748-8583.2010.00158.x 
Li, T., Hou, L., Hu, W. (2011). "An investigation of knowledge sharing on campus among teachers", 2011 International Conference on Management and Service Science, Wuhan, China, IEEE, PP. 1-3. http://dx.doi.org/10.1109/ICMSS.2011.5998908

Liu, Z.-g., Cui, J. (2012). "Improve technological innovation capability of enterprises through tacit knowledge sharing", Procedia Engineering, Vol. 29 No., PP. 2072-2076. http://dx.doi.org/10.1016/j.proeng.2012.01.264

Matoskova, J., Rehackova, H., Sobotkova, E., Polcakova, M., Jurasek, M., Gregar, A., Svec, V. (2013). "Facilitating leader tacit knowledge acquisition", Journal of Competitiveness, Vol. 5 No. $1, \quad$ PP. 3-15. http://dx.doi.org/10.7441/joc.2013.01.01

Mládková, L. (2012). "Sharing tacit knowledge within organizations: evidence from the Czech Republic", Global Journal of Business Research, Vol. 6 No. 2, PP. 105-115. http://dx.doi.org/10.4135/9781446217375

Nicholls, M.G., Cargill, B.J. (2010). "Achieving best practice manufacturing involving tacit knowledge through the cautious use of mixed-mode modelling", International Journal of Sociotechnology and Knowledge Development, Vol. 2 No. 2, PP. 35-52. http://dx.doi.org/10.4018/jskd.2010040102

Nugroho, M.A. (2012). "Correlations of attitude to avoid sharing risk and trust with informal knowledge sharing", International Journal of Economics Business and Management Studies, Vol. 1 No. 3, PP. 86-95.

Okoroafor, H. (2014). "The barriers to tacit knowledge sharing in franchise organizations", Knowledge Management Research \& Practice, Vol. 12 No., PP. 97-102. http://dx.doi.org/10.1057/kmrp.2013.30

Oliver, G. (2014). "Modes of information (knowledge) sharing: a case study", European Conference on Knowledge Management, Kidmore End, United Kingdom, Academic Conferences International Limited, PP. 774-782.

Panahi, S., Watson, J., Partridge, H. (2013). "Towards tacit knowledge sharing over social web tools", Journal of Knowledge Management, Vol. 17 No. 3, PP. 379-397. http://dx.doi.org/10.1108/JKM-11-2012-0364

Polanyi, M. (1966). The tacit dimension. University of Chicago Press, Chicago.

Puccinelli, B. (1998). "Strategies for sharing knowledge", Inform, Vol. 12 No. 9, PP. 40-41.

R, A., Prakasam, S. (2013). "Enhancing cloud based e-learning using knowledge sharing system", International Journal of Computer Applications, Vol. 84 No. 9, PP. 26-30. http://dx.doi.org/10.5120/14606-2857

Ranasinghe, S.B., Dharmadasa, P. (2013). "Intention to knowledge sharing: from planned behavior and psychological needs perspectives", International journal of knowledge management, Vol. 9 No. 4, PP. 33-50. http://dx.doi.org/10.4018/ijkm.2013100103

Richlin, L., Cox, M.D. (2004). Building faculty learning communities. Jossey-Bass, San Francisco.

Scharf, E.R. (2008). "Sharing knowledge in the universities: tacits and explicits knowledge in the classroom", Sistemas \& Gestão, Vol. 3 No. 3, PP. 216-232.

Semradova, I., Hubackova, S. (2014). "Responsibilities and competences of a university teacher", Procedia - Social and Behavioral Sciences, Vol. 159 No., PP. 437-441. http://dx.doi.org/10.1016/j.sbspro.2014.12.403

Shariq, S.Z. (2010). Contexts for tacit knowledge sharing, in: Schwartz, D., Te'eni, D. (Eds.), Encyclopedia of Knowledge Management, 2 ed. Information Science Reference, Hershey, New York, pp. 121-130.

Sharma, B.P. (2015). "Modeling the knowledge sharing barriers: an ISM approach", International Journal of Knowledge-based Organizations, Vol. 5 No. 1, PP. 16-33. http://dx.doi.org/10.4018/ijkbo.2015010102

Shatz, D. (2004). Peer review: a critical inquiry. Rowman \& Littlefield, Lanham, Md.

Shim, H.S., Roth, G.L. (2007). "Sharing tacit knowledge among expert teaching professors and mentees: considerations for career and technical education teacher educators", Journal of Industrial Teacher Education, Vol. 44 No. 4, PP. 5-28.

Siemsen, E., Roth, A.V., Balasubramanian, S., Anand, G. (2009). "The influence of psychological safety and confidence in knowledge on employee knowledge sharing", Manufacturing \& service operations management, Vol. 11 No. 3, PP. 429-447. http://dx.doi.org/10.1287/msom.1080.0233

Singleton, B. (2015). "Peer review", Contemporary Theatre Review, Vol. 25 No. 1, PP. $26-29$. http://dx.doi.org/10.5935/0004-2749.20150001

Sita Nirmala Kumaraswamy, K., Chitale, C.M. (2012). "Collaborative knowledge sharing strategy to enhance organizational learning", Journal of Management Development, Vol. 31 No. 3, PP. 308-322. http://dx.doi.org/10.1108/02621711211208934

Sivak, A., Koch, K. (2012). "Process mapping for teamwork and knowledge sharing", Feliciter, Vol. 58 No. 5 , PP. 
19-20.

Song, S. (2002). "An internet knowledge sharing system", Journal of Computer Information Systems, Vol. 42 No. 3 , PP. 25-30.

Stewart, T. (2012). "Knowledge sharing", Behaviour \& Information Technology, Vol. 31 No. 11, PP. 1055-1056. http://dx.doi.org/10.1080/0144929X.2012.745277

Sumi, Y., Mase, K. (2002). "Conference assistant system for supporting knowledge sharing in academic communities", Interacting with Computers, Vol. 14 No. 6, PP. 713-737. http://dx.doi.org/10.1016/S0953-5438(02)00018-8

Suppiah, V., Sandhu, M.S. (2011). "Organisational culture's influence on tacit knowledge-sharing behaviour", Journal of Knowledge Management, Vol. 15 No. 3, PP. 462-477. http://dx.doi.org/10.1108/13673271111137439

Ting, S.L., Wang, W.M., Tse, Y.K., Ip, W.H. (2011). "Knowledge elicitation approach in enhancing tacit knowledge sharing", Industrial Management and Data Systems, Vol. 111 No. 7, PP. 1039-1064. http://dx.doi.org/10.1108/02635571111161280

Tsai, A. (2014). "An empirical model of four processes for sharing organisational knowledge", Online Information Review, Vol. 38 No. 2, PP. 305-320. http://dx.doi.org/10.1108/OIR-03-2013-0059

Tschetter, J., Tschetter, E. (2012), "Perspectives on tacit knowledge", Journal of Organizational Psychology, Vol. 12 No. 2, PP. 125-129.

Venkitachalam, K., Busch, P. (2012). "Tacit knowledge: review and possible research directions", Journal of Knowledge Management, Vol. 16 No. 2, PP. 365-371. http://dx.doi.org/10.1108/13673271211218915

Wendling, M., Oliveira, M., Carlos Gastaud Maçada, A. (2013). "Knowledge sharing barriers in global teams", Journal of Systems and Information Technology, Vol. 15 No. 3, PP. 239-253. http://dx.doi.org/10.1108/JSIT-09-2012-0054

Whalan, F. (2012). Teacher-to-teacher trust and collective responsibility, Collective responsibility redefining what falls between the cracks for school reform. Sense Publishers, pp. 139-154. http://dx.doi.org/10.1007/978-94-6091-882-7_7

Xiaohui, Y. (2012). "Study on knowledge sharing mechanism of university teachers in information age", 2012 First National Conference for Engineering Sciences, Baghdad, Iraq, IEEE, PP. 1701-1704. http://dx.doi.org/10.1109/NCES.2012.6543805

Xiaojun, L., Zongkui, Z., Yumei, Z. (2011). The influence of the university teachers' psychological contract on knowledge sharing, Electrical Power Systems and Computers. Springer Berlin Heidelberg, pp. 253-258. http://dx.doi.org/10.1007/978-3-642-21747-0_31

Xue, Y., Liang, H., Hauser, R., O'Hara, M. (2012). "An empirical study of knowledge sharing intention within virtual teams", International journal of knowledge management, Vol. $^{8}$ No. 3, PP. 47-61. http://dx.doi.org/10.4018/jkm.2012070103

Yang, H.-1., Wu, T.C.T. (2008). "Knowledge sharing in an organization", Technological Forecasting \& Social Change, Vol. 75 No. 8, PP. 1128-1156. http://dx.doi.org/10.1016/j.techfore.2007.11.008

Yoo, D., No, S. (2014). "Ontology-based economics knowledge sharing system", Expert Systems with Applications, Vol. 41 No. 4, PP. 1331-1341. http://dx.doi.org/10.1016/j.eswa.2013.08.031

Yoon, S.W., Matsui, M., Yamada, T., Nof, S.Y. (2011). "Analysis of effectiveness and benefits of collaboration modes with information- and knowledge-sharing", Journal of Intelligent Manufacturing, Vol. 22 No. 1, PP. 101-112. http://dx.doi.org/10.1007/s10845-009-0282-x

Zeng, G. (2014). "Knowledge sharing in a virtual community of a hotel association: from free riders to active knowledge sharers", Journal of China Tourism Research, Vol. 10 No. 1, PP. 95-119. http://dx.doi.org/10.1080/19388160.2013.847133

Zhang, P., Fai Ng, F. (2012). "Attitude toward knowledge sharing in construction teams", Industrial Management and Data Systems, Vol. 112 No. 9, PP. 1326-1347. http://dx.doi.org/10.1108/02635571211278956

Zhang, Y., Fang, Y., Wei, K.-K., Chen, H. (2010). "Exploring the role of psychological safety in promoting the intention to continue sharing knowledge in virtual communities", International Journal of Information Management, Vol. 30 No. 5, PP. 425-436. http://dx.doi.org/10.1016/j.ijinfomgt.2010.02.003

Zhong, X., Qu, K. (2012). "Research on the model construction of teachers' tacit knowledge sharing based on social software", Procedia Engineering, Vol. 29 No., PP. 223-228. http://dx.doi.org/10.1016/j.proeng.2011.12.698 